\title{
Reactive Oxygen Species of Ozonolysis Products of Some Unsaturated Organic Compounds
}

DOI: $10.17691 / \mathrm{stm} 2019.11 .3 .08$

Received May 13, 2019

A.S. Gordetsov, DSc, Professor, Head of General Chemistry Department";

S.P. Peretyagin, MD, DSc, Professor2;

A.V. Kadomtseva, PhD, Senior Teacher, General Chemistry Department';

A.N. Novikova, PhD, Senior Teacher, General Chemistry Department';

O.V. Grechkaneva, Researcher';

S.V. Zimina, PhD, Associate Professor, General Chemistry Department ${ }^{1}$

${ }^{1}$ Privolzhsky Research Medical University, 10/1 Minin and Pozharsky Square, Nizhny Novgorod, 603005, Russia;

${ }^{2}$ Ozone Therapeutist Association, 9 Panin St., Nizhny Novgorod, 603089

The aim of the investigation was to study the composition of reaction systems formed when certain lipids are ozonized, in particular, olive oil lipids and olive oil model system - oleic acid, as well as to reveal reactive oxygen species (ROS) in the systems resulting in sanogenetic properties appearing in preparations based on the properties.

Materials and Methods. Lipids containing oleic acid in esterified and free forms were ozonized by an ozone therapy unit with an ozone destructor (Medozons-03, AOT-N-01-Arz-01, Russia). The chemical composition and structure of ozonolysis products containing ROS were studied using Fourier-transform IR spectrophotometer (Shimadzu IR Prestige 21, Japan) in a wave number area $4000-400 \mathrm{~cm}^{-1}$ in the form of liquid films in the windows from $\mathrm{KBr}$ or $\mathrm{ZnSe}$. ROS were searched by comparing IR spectra of studied samples before and after ozonolysis. The dynamics of ROS formation and concentration changes were also controlled by iodometric titration according to Interstate standard GOST ISO 3960-2013. The properties of medicinal preparations made on ozonized products, as well as ROS concentration changes were studied in a similar way.

Results. Fourier-transform IR spectroscopy enabled to find that the ozonolysis of lipids containing oleic acid in esterified and free forms results in the formation of hydroperoxyacids and hydroperoxyesters, respectively, rather than ozonides, as basic relatively stable ROS forms. The concentration of ozonides is rather low, while hydroperoxy-derivatives segregate rather slowly, and exist in reaction products (systems) within several months. Multi-component hydrophilic bases of pharmaceuticals have a slight direct chemical effect on this ROS type.

Key words: Fourier-transform IR spectroscopy; ozone; hydroperoxyacids; hydroperoxyesters.

\section{Introduction}

For the past 2-3 decades external ozonidecontaining pharmaceuticals have been successfully administered medicinally in different areas of medicine (dermatovenerology, gynecology, dentistry, combustiology). Moreover, some years ago, leading global manufacturers in several countries: Russia, Ukraine, Italy, Cuba, Spain, Turkey, USA, Mexico — set up the production of pharmaceuticals for external use containing ozone-chemically modified lipids like olive oils [1]. It promotes more intensive study of the chemical composition of reaction mixtures formed.

Ozonide-containing preparations being in demand in the medical market are marketed as those having a powerful bactericidal effect, antioxidant characteristics, the ability to improve blood circulation, promote cell regeneratory potential through the intensification of aerobic metabolism processes [2]. However, the development of new pharmaceuticals containing reactive oxygen species - ROS (oils, hydrophilic substances) requires physicochemical and biochemical studies to

Corresponding author: Alexander S. Gordetsov, e-mail: algordetsov@yandex.ru 
establish their composition and biological characteristics resulting from a technical process.

The aim of the investigation was to study the composition of reaction systems formed when certain lipids are ozonized, in particular, olive oil lipids and olive oil model system - oleic acid, as well as to reveal reactive oxygen species in the systems resulting in sanogenetic properties appeared in preparations based on the properties.

\section{Materials and Methods}

Lipids containing oleic acid in esterified and free forms were ozonized by an ozone therapy unit with low concentration and an ozone destructor (Medozons-03, AOT-N-01-Arz-01; Medozons, Russia). The chemical composition and structure of ozonolysis products containing ROS were studied using Fourier-transform IR spectrophotometer (Shimadzu IR Prestige 21; Shimadzu Corp., Japan) in a wave number area $4000-400 \mathrm{~cm}^{-1}$ in the form of liquid films in the windows from $\mathrm{KBr}$ or $\mathrm{ZnSe}$. ROS were identified by comparing IR spectra of studied samples before and after ozonolysis. ROS concentration was also determined by iodometric titration according to Interstate standard GOST ISO 3960-2013 [3]. The properties of medicinal preparations made on ozonized products were studied in a similar way.

\section{Results and Discussion}

Organic compounds containing olefinic carbon-tocarbon bonds when being ozonized are known to cause carbon-to-carbon bond cleavage forming oxidative products, ozonides being basic among others [4, 5]. However, if reactions are carried out with alcohols, acids and other acid-containing substances, peroxide products of other types are formed instead of ozonides [5, 6], for example, according to scheme 1 :

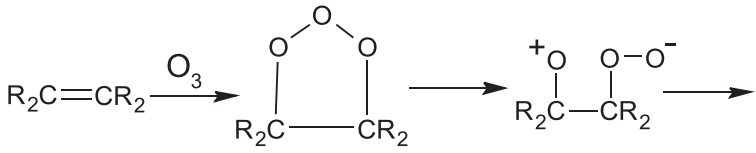

$$
\begin{aligned}
& \longrightarrow \mathrm{R}_{2} \mathrm{C}=\mathrm{O}+\overline{\mathrm{O}}-\mathrm{O}-\stackrel{+}{\mathrm{C}} \mathrm{R}_{2}
\end{aligned}
$$

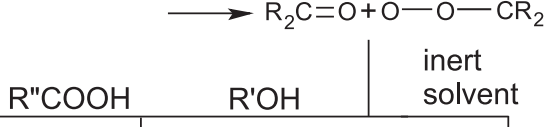

$$
\begin{aligned}
& \underset{\mathrm{R}{ }^{2} \mathrm{C}-\mathrm{OH}}{-\mathrm{OR}^{\prime}}+\mathrm{R}_{2} \mathrm{C}=\mathrm{O} \\
& \left.\right|_{\substack{\mathrm{O}^{-} \\
\text {polymer } \\
\text { ozonide }}} ^{\mathrm{C}}
\end{aligned}
$$

en unsaturated compounds react with ozone in a ketone medium, ozonide yield decreases from 86.6 to $2.9 \%$, peroxides and lactones being the basic products [5]. It should be noted that when oleic acid is treated with ozone in a nonanoic acid (pelargonic) medium, then, instead of ozonides, at first hydroperoxyacid is formed, which then goes into the mixture of nonanoic and anchoic acids [5]. The reaction is used for anchoic acid manufacturing (scheme 2):

$$
\underset{-\mathrm{C}_{8} \mathrm{H}_{17} \mathrm{COOH}}{\mathrm{C}_{8} \mathrm{H}_{17} \mathrm{COOH}}
$$

We took interest in the relation of free and esterified oleic acid to ozone exposure under the conditions of derma-cosmetic cream production, since their basic component is ozonized olive oil.

Oleic acid ozonolysis was carried out according to the technique and under the conditions similar to those of olive oil ozonolysis. IR spectra of initial substance and the mixture of ozonization products showed that intermediate hydroperoxide (B) forms, in addition to the expected nonanoic and anchoic acids as one of the main products (scheme 3 ):

$$
\begin{aligned}
& \mathrm{CH}_{3}-\left(\mathrm{CH}_{2}\right)_{7}-\mathrm{CH}=\mathrm{CH}-\left(\mathrm{CH}_{2}\right)_{7} \mathrm{COOH} \stackrel{\mathrm{O}_{3}}{\longrightarrow} \\
& \stackrel{\mathrm{O}_{3}}{\longrightarrow} \mathrm{H}_{3} \mathrm{C}-\left(\mathrm{CH}_{2}\right)_{7}-\overbrace{\text { Ozonide }(\mathrm{A})}^{\mathrm{CH}-\left(\mathrm{CH}_{2}\right)_{7} \mathrm{COOH} \longrightarrow}
\end{aligned}
$$

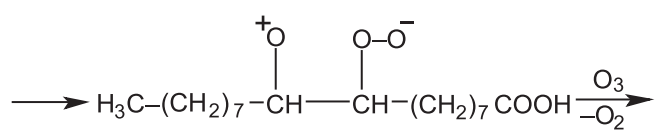

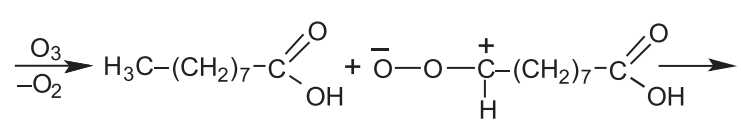

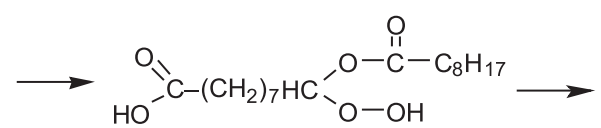

$$
\begin{aligned}
& \text { hydroperoxyacid (B) } \\
& \longrightarrow \text { HO } \stackrel{\mathrm{O}}{\mathrm{O}}-\left(\mathrm{CH}_{2}\right)_{7}-\mathrm{C}_{\mathrm{OH}}^{\prime}+\mathrm{C}_{8} \mathrm{H}_{17} \mathrm{COOH}
\end{aligned}
$$

IR spectra of reaction mixture (Figure $1(a),(b))$ were found to have the following absorption bands $\left(\mathrm{cm}^{-1}\right)$ : hydroperoxyacid $(\mathrm{B})-3450$ (valence vibrations $\mathrm{H}-\mathrm{O}$ in a free HOO group), 1740 (valence vibrations of $\mathrm{C}=\mathrm{O}$ group in peroxy acids), 1095 (valence vibrations $\mathrm{C}-\mathrm{O}-\mathrm{O}$ ), 885 (valence vibrations of $\mathrm{O}-\mathrm{O}$ group, poor absorption); nonanoic acid - 1711 (valence vibrations 


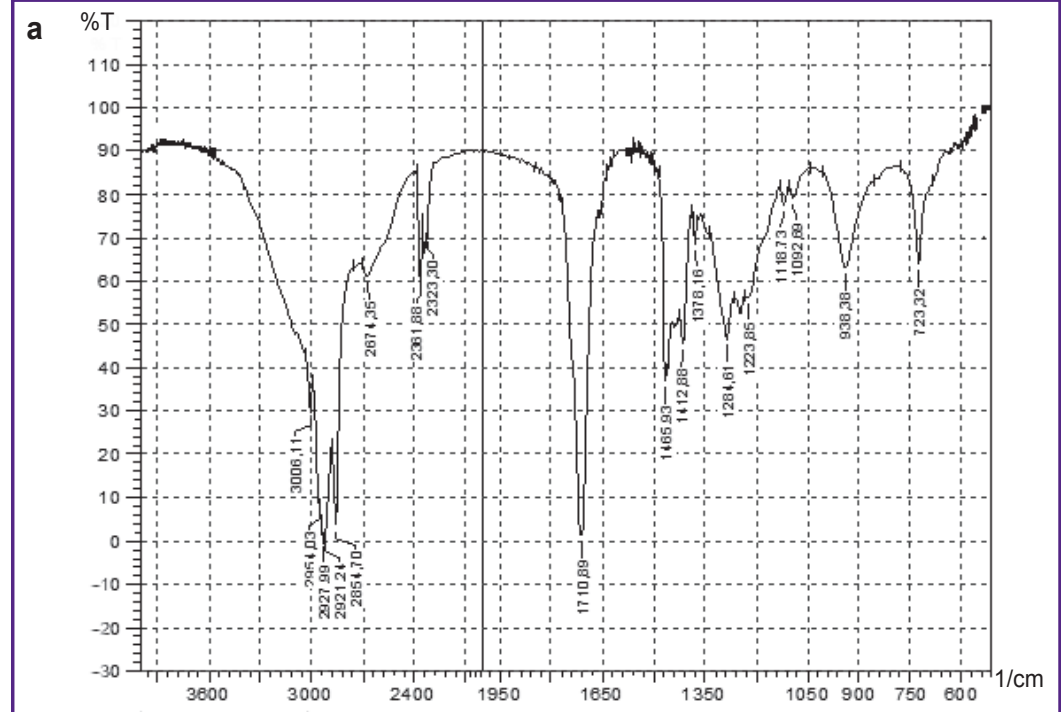

b $\%$ T

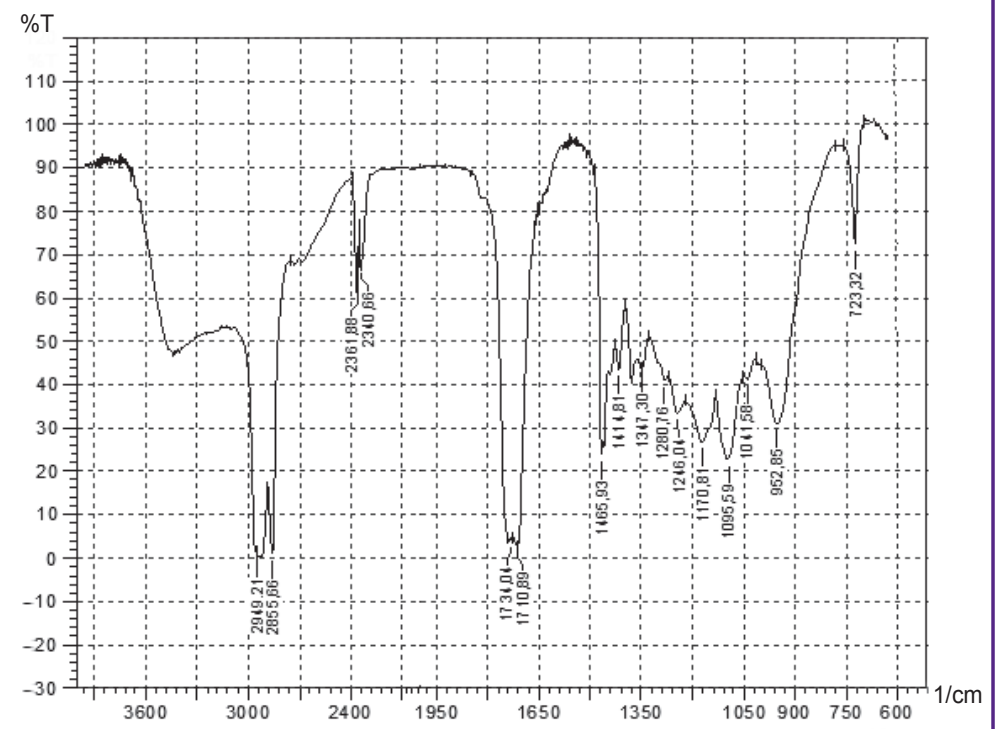

c

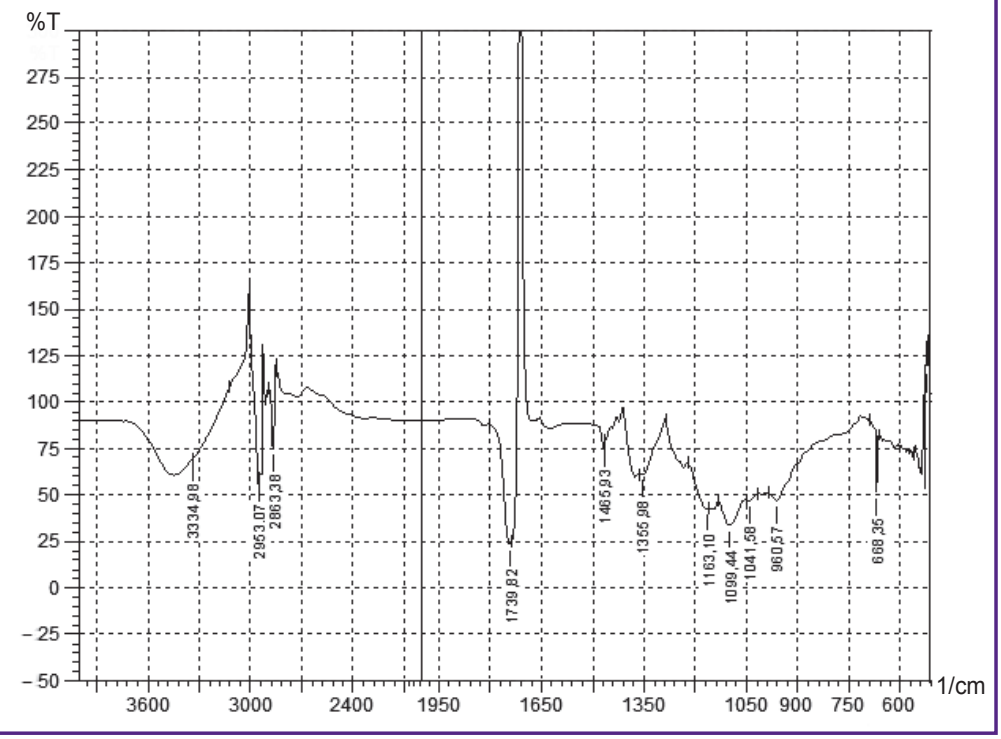

Figure 1. IR spectrum of:

(a) oleic acid; (b) oleic acid ozonization products; (c) hydroperoxyacids, the spectrum being obtained by subtracting oleic acid IR spectra before and after ozonolysis
$\mathrm{C}=0$ ), $1465,1412,1287,1220,950$; anchoic acid - 1690 (shoulder, valence vibrations $\mathrm{C}=\mathrm{O}$ ), 2932, 2856 (valence vibrations $\mathrm{C}-\mathrm{H}$ ), 1469, 1434 (deformation vibrations $\mathrm{C}-\mathrm{H}$ ). There was also found a low intensity peak $1041 \mathrm{~cm}^{-1}$, which appears to belong to ozonide (A) [5]. There is sight impurity of oleic acid. IR spectrum stripping $[7,8]$ confirmed the main absorption peaks of $\mathrm{C}=\mathrm{O}$ hydroxyperoxide (B) (Figure 1 (c)). Thus, hydroperoxyacid and ozonide are ROS carriers in the reaction (3).

Ozonides are known [5, 9] to form resulting from olive oil ozonized using similar schemes, and ozonides in the presence of oxidation products are quickly changed into hydroperoxides of fatty acids and compound ethers. However, ester groups of triglycerides are also distructed producing various mono- and diglycerides with peroxide groups. In the end, the result is a complex mixture of oxidation products of organic substances, and among them there can be identified aldehydes, ketones, short-chain and long-chain carboxylic acids, as well as peroxide and hydroperoxide derivatives of the above-mentioned compounds. Some ozonization products are proved by gas and thin-layer chromatography, nonanoic acid having the highest concentration among the identified substances [9].

The study of the initial and ozonized olive oil by IR spectra showed that under the technical process the reaction is deep, and the basic products are peroxy acids and their ethers (scheme 4) and also nonanoic acid. IR spectra of the reaction products mixture (Figure 2) have the following main absorption bands $\left(\mathrm{cm}^{-1}\right) ; 3478-3468(v \mathrm{OOH}), 1754$ ( $v \mathrm{C}=0$ ), 1464, 1418, 1101 ( $v$ COO), 885 ( $\vee \mathrm{O}-\mathrm{O}$, shoulder) [hydroperoxyacids and their ethers] [4], 1718-1712 ( $\vee \mathrm{C}=0)$, 1464, 1418, 1243, 1105, 954 [nonanoic acid]. There is also an absorption band at $1050 \mathrm{~cm}^{-1}$ [ozonides]. Thus, similar to oleic acid, ROS carriers are hydroperoxyacids and their esters, as well as a few ozonides.

It should be noted that ROS peak intensity in IR spectra of the reaction products (4) is slightly lower than in oleic acid ozonization. No hydrolysis of oleates and other olive oil triglycerides was observed. For example, in IR spectra 
there are no absorption bands of glycerol, the main hydrolysis product. Moreover, special experiments showed that glycerol itself does not react with ozone under the conditions applied. Estimated ozonolysis triolein, which is the major component of olive oil, has the same appearance for a single lipid fragment (scheme 4):

$$
\begin{aligned}
& \stackrel{-}{-}-\mathrm{O}-\mathrm{O}-\mathrm{C}-\left(\mathrm{CH}_{2}\right)_{7}-\mathrm{CH}=\mathrm{CH}-\left(\mathrm{CH}_{2}\right)_{7}-\mathrm{CH}_{3} \stackrel{\mathrm{O}_{3}}{\longrightarrow}
\end{aligned}
$$

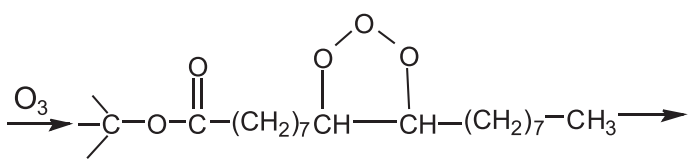

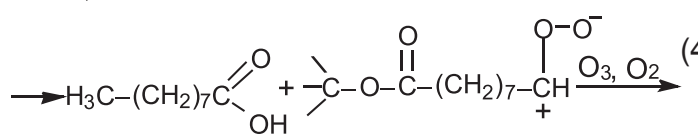

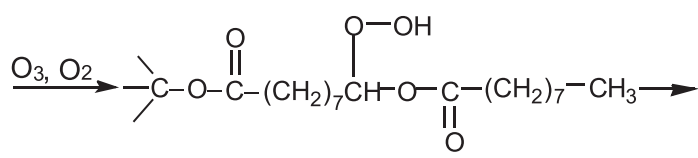

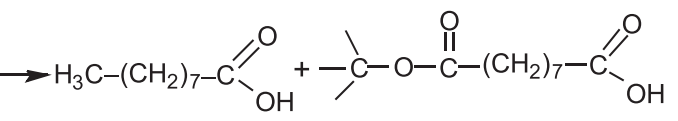

It is obvious that the reaction cannot proceed just in three, or in two or even in one ether substitute fragment in the lipid; moreover, the resulting substances are further hydrolyzed and oxidized producing the mixture of mono-, di-, and triglycerides of more short-chain acids [9], as well as different aldehydes and free acids. It is evident that among the ozonolysis products of olive oil there should be all the products of the reaction between free oleic acid and ozone (scheme 3), though their total concentration is about $1 \%$, since free acid concentration in oil does not exceed $1-2 \%$.

In the end of the study, we carried out IR spectroscopic analysis of medicinal preparations based on ozonized olive oil added to water suspension of a multi-component base of a medical cream consisting of compound ethers, salts of long-chain carboxylic acids and polymer alcohols. As expected, the principal absorption bands of cream base samples correspond to characteristic water frequencies with maximum at 3400-3300, 2083, and $1647 \mathrm{~cm}^{-1}$. When ozonized oil was added to the base and the oil concentration increased from 3 to $30 \%$, there was observed the gradual intensity growth of absorption bands within the range $\sim 1745$ $1717 \mathrm{~cm}^{-1}$ (valence vibrations $\mathrm{C}=\mathrm{O}$ mixture of olive oil ozonizing reaction products).

The absorption band with its maximum at $1106 \mathrm{~cm}^{-1}$ (v C-O-O peroxy compounds) actually does not appear in 3, 5, and $10 \%$ creams, however, it is rather intensive in $30 \%$ cream. Most probably, low concentration ROS
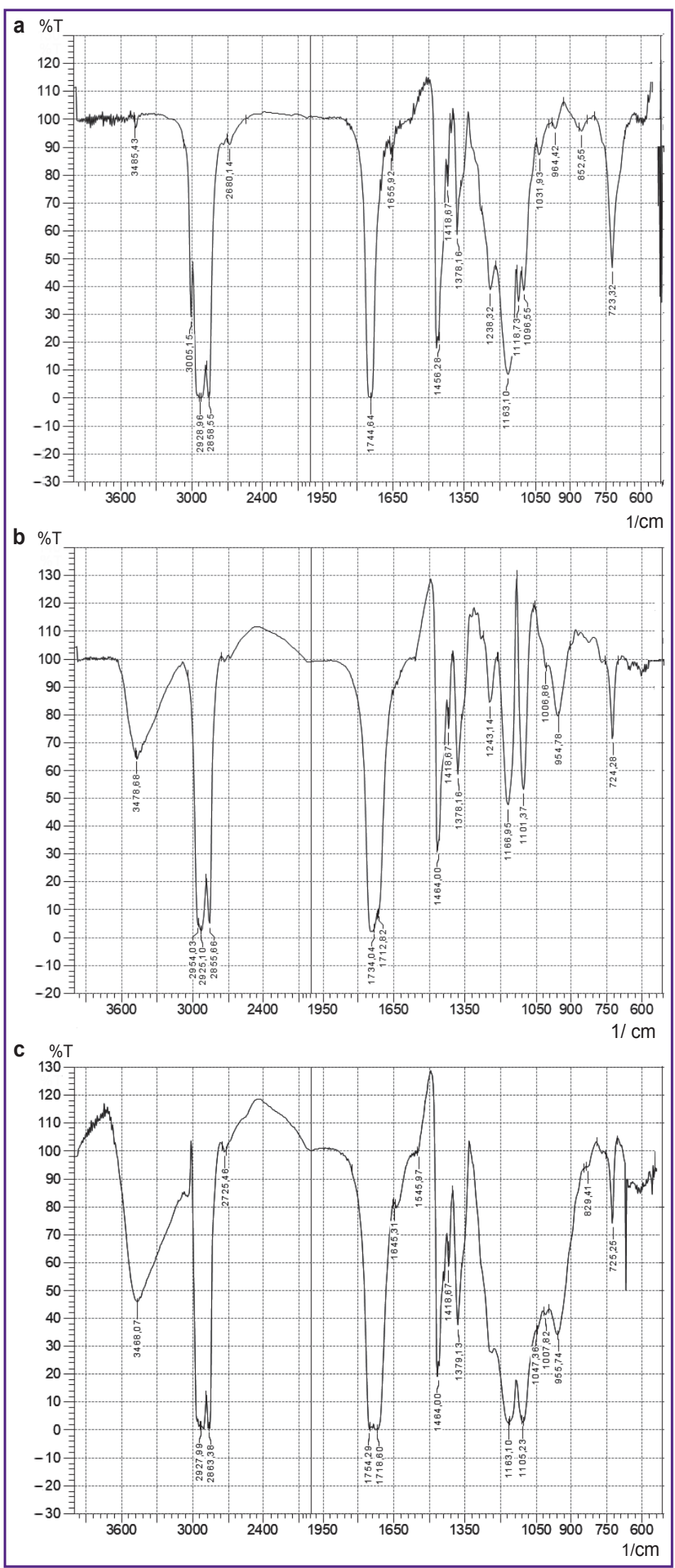

Figure 2. IR spectrum of:

(a) olive oil; (b) olive oil ozonization products; (c) hydroperoxyethers, the spectrum being obtained by subtracting olive oil IR spectra before and after ozonolysis 
nearly completely react with the base, ester constituents of which (e.g., isopropyl myristate) increase solubility of olive oil acylglycerols transforming it into a homogeneous phase with unsaturated components. The latter is likely to undergo Prilezhaev reaction yielding a-oxides and then glycols (scheme 5):<smiles>[R]C=C([R])[GeH2]O[Na]</smiles>

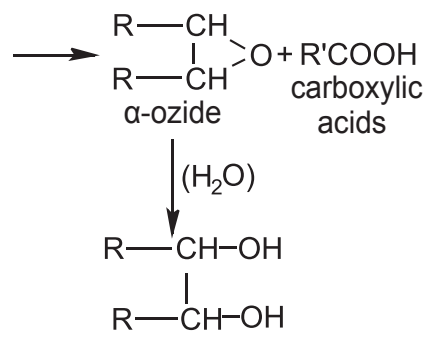

Moreover, we expect the direct formation of carboxylic acids and atomical oxygen, which can explain a bleaching effect of peroxyacids [4] (scheme 6):<smiles>[R]C(=O)OO</smiles>

It is noteworthy that IR spectra of $30 \%$ cream can change when stored for several months. For example, after a 3-month period the main peak of $v \mathrm{C}=\mathrm{O}$ is 1750-1741 $\mathrm{cm}^{-1}$ ( $v \mathrm{C}=\mathrm{O}$ hydroperoxy compounds), after 6 months - averaged $v \mathrm{C}=\mathrm{O}-1733 \mathrm{~cm}^{-1}$, and after 8 months $-1716 \mathrm{~cm}^{-1}$. It means gradual breakdown of ROS and lipids when preparations are in storage.

\section{Conclusion}

During the ozonization of olive oil lipids and olive oil model system - oleic acid, as ROS there form hydroperoxyacids and hydroperoxyesters, respectively, and ozonides being contained only in the form of impurities. Ozonized olive oil-based medicinal preparations reserve the function of ROS carriers for long enough. The dynamics of chemical transformations with ROS participation can be controlled by Fouriertransform IR spectroscopy.

Study funding and conflicts of interest. The study had no funding sourcing, and there are no conflicts of interest related to the present study.

\section{References}

1. Grechkanyova O., Bitkina O., Peretyagin S., Peretyagin P., Gabasov I., Razheva P. The usage of laser Doppler flowmetry for evaluation of the efficiency of ozonecontaining drugs for external use. J Pharm Pharmacol 2018; 6(1): 3238, https://doi.org/10.17265/2328-2150/2018.01.004.

2. Peretyagin S.P., Gordinskaya N.A., Struchkov A.A., Gordetsov A.S. Chemical properties, biological activity and bioavailability of ozonized oil. Kazanskij medicinskij zurnal 2007; 88(4): 101-102.

3. GOST ISO 3960-2013 Zhiry i masla zhivotnye $i$ rastitel'nye [GOST ISO 3960-2013 Animal and vegetable fats and oils]. 2015.

4. Khimicheskaya entsiklopediya. T. 3 [Chemical encyclopedia. Vol. 3]. Moscow: Bol'shaya Rossiyskaya entsiklopediya; 1992; 639 p.

5. Razumovskii S.D., Zaikov G.E. Kinetics and mechanism of the reaction of ozone with double bonds. Russian Chemical Reviews 1980; 49(12): 1163-1180, https://doi.org/10.1070/ rc1980v049n12abeh002535.

6. Rieche A., Schulz M., Becker D. Ozonisierung von Olefinalkoholen. Bildung von Hydroperoxyden cyclischer Äther. Chem Ber 1965; 98(11): 3627-3631, https://doi.org/10.1002/ cber.19650981129.

7. Vytovtov A.A. Identification and detection of adulteration of food products by the method of the infrared Fourier spectrometry. Uchenye zapiski Sankt-Peterburgskogo im. V.B. Bobkova filiala Rossiyskoy tamozhennoy akademii 2010; 1(35): 193-196.

8. Mishina N.E., Zilberman B.Ya., Kol'Tsova T.I., Lumpov A.A., Puzikov E.A. Composition of precipitates of barium and strontium nitrates crystallizing from nitric acid solutions. Radiochemistry 2014; 56(3): 252-261, https://doi. org/10.1134/s1066362214030060.

9. Rainbauer H., Washüttl J., Steiner I., Kroyer G., Winker N., Streichsbier F. Chemische Untersuchungen an ozonisiertem Olivenöl. Fette, Seifen, Anstrichmittel 1982; 84(5): 188-191, https://doi.org/10.1002/lipi.19820840506. 